To address this gap, the field of implementation science is now answering many of the questions about how to produce consistent, positive outcomes in real-world settings. This talk will address the successful drivers behind effective implementation and tools for assessing your organisation's readiness for implementation.

\section{SNOW'D IN: TRANSLATING RESEARCH INTO PRACTICE}

Dale Hanson. James Cook University, Australia

\subsection{6/injuryprev-2016-042156.4}

John Snow's investigation of the 1854 cholera outbreak in London is portrayed as a classic example of epidemiology informing real world implementation.

The public discourse regarding cholera in Victorian London was more fraught than is generally appreciated today.

Snow suspected that cholera was transmitted by contaminated water. At a time when disease was believed to be spread by miasma (foul air), Snow's views were revolutionary.

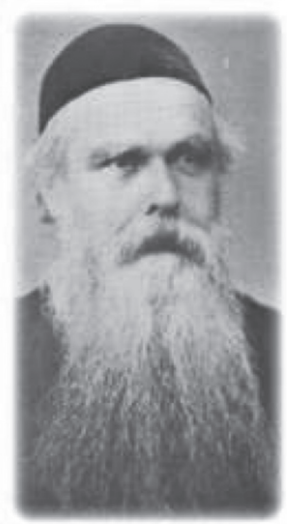

Snow's story will be retold in the person of his friend and colleague Rev Henry Whitehead. 600 of Whitehead's parishioners died in the epidemic. Though initially sceptical of Snow's theories, he investigated the outbreak using his strong network of relationships with the people of Soho, identifying the sentinel case and source of contamination of the Broad Street Well.

Snow had died when cholera returned to London in 1865/66, leaving Whitehead the main authority on the Broad Street outbreak. Whitehead worked with the Government Statistician William Farr's staff to identify the source of the outbreak. This time Farr was convinced and took up the cause.

Arguably, the real driver for reform may have been political. It was not until the "big stink," when the heavily contaminated Thames became so disgusting that it threatened to close the newly opened House of Commons, that politicians found the motivation to pass legislation ensuring clean water.

The ferocious public discussion regarding cholera in Victorian England has many parallels with contemporary public health debates. While Snow's theories have subsequently been proven, he did not win the argument. Others who were more politically savvy and socially better connected did that.

"Dr Snow's views on cholera," said a medical friend to me in 1855, "are generally regarded in the profession as very unsound. If that be the case," I replied, "then heresy may be as good a thing in your profession as some of you are apt to suppose it is in mine." Reverend Henry Whitehead (1825-1896).

\section{Plenary Session \\ Monday 19.9.2016 9:30-10:30 \\ Safety in all Policies}

\section{USING "HEALTH IN ALL POLICIES" - FRAMEWORK TO INTEGRATE SAFETY}

Francesca Racioppi. World Health Organisation (WHO) Regional Office for Europe Copenhagen, Denmark;

\section{(C) World Health Organization 2016. License BMJ.}

Disclaimer: The author is a staff member of the World Health Organization. The author alone is responsible for the views expressed in this publication and they do not necessarily represent the views, decisions or policies of the World Health Organization.

\subsection{6/injuryprev-2016-042156.5}

Background "Health in all policies (HiAP) is an approach to public policies across sectors that systematically takes into account the health and health systems implications of decisions, seeks synergies and avoids harmful health impacts, in order to improve population health and health equity" (Health in all policies Seizing opportunities, implementing policies. Copenhagen: WHO Regional Office for Europe; 2013).

Description of the problem Drawing from the HiAP approach, a "safety in all policies" (SiAP) framework could help integrating safety into sectoral policies, such as those of transport, infrastructure, housing, leisure, entertainment, sport, justice, education, labour, social services and industry. This calls for "whole-of-government" and "whole-of-society" approaches, as well as for "system approaches". Through these, safety could become a key component of sectoral performance, and contribute to increasing efficiency, enhancing sectoral performance, reducing inequalities and preventable loss. SiAP entails ownership and accountability for safety by relevant sectors, and promotes a shift towards a proactive identification and management of risks. It could also promote new partnerships between the safety community and different sectors, benefiting from an evidence-based public health approach to safety.

Results With several of the Sustainable Development Goals (SDGs) including targets related to safety, SiAP may support the attainment of the SDGs. On the other side, the SDGs provide additional legitimacy and facilitate the implementation of SiAP by placing safety targets squarely within relevant policy domains.

Conclusions SiAP requires a cultural shift, and the development of a robust understanding and appreciation of the long-term health, developmental and economic benefits offered by integrating safety in sectoral policies. It may also require changes to institutional accountability frameworks and to how sectoral performance gets appraised.

\section{CREATING MORE PEACEFUL SOCIETIES: GLOBAL STRATEGIES TO REDUCE INTERPERSONAL VIOLENCE}

Manuel Eisner. Professor of Developmental and Comparative Criminology, Violence Research Centre Institute of Criminology, University of Cambridge

\subsection{6/injuryprev-2016-042156.6}

The 2030 Sustainable Development Goals (SDGs) have put violence reduction at the heart of global efforts to create sustainable societies. Goal 16 is entirely devoted to the promotion of 
peaceful societies and the rule of law and target 16.2 sets the goal of ending abuse, exploitation, trafficking and all forms of violence against and torture of children. The SDG agenda is an extraordinary window of opportunity to make significant progress towards reducing all forms of interpersonal violence. However, it also poses vast challenges. Achieving significant population-level reductions across the world within less than two decades presents a task for policy and research at a scale for which no precedent exists in the field of violence prevention.

In my talk I will outline the knowledge and strategies needed to meet this challenge. I will argue, first, that scientific evidencebased on randomised trials is important, but not sufficient. We also need to understand the mechanisms that drive major population-wide declines such as the violence drop in many high-income countries over the past 20 years. Second, research on major violence declines across the world suggests that specific violence prevention programming played a subordinate role in the reduction of violence at the population level. A more comprehensive approach should integrate emerging knowledge about the effects of broader public health policies, for example in the field of the prevention and treatment of mental health more generally. Finally, I will argue that the widespread view of an opposition between repression and prevention needs to be overcome. A multi-sectorial approach should include effective policing and legitimate justice institutions much as early prevention, promotion of social and cognitive skills, situational strategies and victim protection.

\section{FROM MANAGING DISASTERS TO MANAGING RISKS, REDUCING EXISTING RISKS}

Mette Lindahl Olsson. Swedish Civil Contingencies Agency, MSB and Former Swedish Secondment as Program Officer to the UNISDR, the United Nations Office for Disaster Risk Reduction, Europe Office in Brussels

\subsection{6/injuryprev-2016-042156.7}

We live in an urbanising, complex world with a rapidly changing climate. To reduce vulnerability and to protect inhabitants from current and future risks we all face the challenge of building resilience. If vulnerable elements as population, property, infrastructure or environment come in the way of events caused by nature or human activity it can cause serious negative consequences and disasters. The vulnerability of society in the face of disasters, especially caused by natural events, is expected to increase. Collaboration on all levels, nationally and internationally, between sectors and actors working with land use planning, risk management, infrastructure planning, health, disaster management and climate adaptation is a pre-requisite to reduce underlying risk factors and enhance society's ability to cope with hazards and risk.

It's clear that disaster risk reduction is an investment, not a cost. Studies show that every dollar invested into disaster preparedness saves seven dollars in disaster aftermath.

In March 2015 at the third World conference on Disaster Risk Reduction in Japan a clear shift in focus from disaster management to disaster risk management was agreed with the Sendai Framework for Disaster Risk Reduction 2015-2030. UNISDR is the UN Focal Point for Disaster Risk Reduction and the implementation of the Sendai Framework and its extension to include both natural and man-made hazards as well as associated environmental, technological and biological hazards is strongly supported by the EU and its member states. At the heart of the framework is the aim to prevent the creation of new risks and to reduce existing levels of disaster risks.
In Sweden the Swedish Civil Contingency Agency (MSB) is the national Sendai Focal Point with the task to further strengthen the multi-sectoral coordination and the implementation of the Sendai Framework.

\section{Plenary Session Tuesday 20.9.2016 9:30-10:30 Safety and Sustainable Development}

\section{MAKING THE ROAD SAFETY SDG TARGETS COUNT: DELIVERING QUICK WINS FOR ROAD TRAFFIC INJURY PREVENTION}

Saul Billingsley. Director, FIA Foundation, UK

10.1136/injuryprev-2016-042156.8

Since January 2016 the new Sustainable Development Goals (SDGs), ${ }^{1}$ or 'Global Goals' have been in force. The decision by negotiators from 190 countries, endorsed by world leaders, to include in these Goals an ambitious and accelerated road safety target to halve road deaths by 2020 demonstrates a recognition of the scale of this appalling human epidemic and the need for urgent action to reduce the preventable toll of death and injury caused by road traffic crashes.

With less than five years remaining to achieve the target, quick and early results are essential. Governments established the deadline, and governments must lead in reaching the objective. The top ten countries by population (China, India, Brazil, Indonesia, Japan, USA, Nigeria, Bangladesh, Pakistan and Russia) together account for an estimated 725,794 road fatalities. Achieving the SDG target of a 50\% reduction in road traffic deaths in these countries would contribute more than half $(362,897)$ the necessary 600,000 reduction in annual deaths. ${ }^{2}$ So, as an essential step, governments in these ten countries need to commit, at the highest level, to tackling an epidemic which is killing their citizens on an industrial scale.

Some governments must also urgently recognise the true scale of their road traffic fatality problem which current injury data collection methods are not capturing. This is important for building public and political support for action, and for effectively identifying and targeting risk factors. For example, China estimates deaths of 58,539 , which equates to a rate per 100,000 of just over 4 . The WHO estimate is 261,367 , or 18.8 per 100,000 ; India estimates $137,572,70,000$ fewer than the WHO estimate; Nigeria officially estimates road traffic deaths of 6,450 . The WHO point estimate is $35,641 .^{3}$ Understanding and accepting the scale of the problem is a vital first step to dealing with it.

The means of implementation and financing will also be key to effective delivery, and moving from words on a communique to measurable action on the ground. For the road safety sector there are three key challenges.

The first is to secure sufficient international catalytic financing to assist governments of middle- and low-income countries to take the initial steps - building the institutional capacity, political will and evidence base - necessary to unlock sustainable sources of domestic funding to deliver long-term road safety strategies. To encourage donors to invest strategically, the global road safety community should be offering a united front, and an obvious place to convene. There is currently discussion, led by the UNECE, and given support by the UN General Assembly, ${ }^{4}$ on 